\title{
Effect of a low-carbohydrate diet versus a low-fat, calorie-restricted diet on adipokine levels in obese, diabetic participants
}

This article was published in the following Dove Press journal:

Diabetes, Metabolic Syndrome and Obesity:Targets and Therapy

12 October 2010

Number of times this article has been viewed

\author{
Marion L Vetter ${ }^{1,2,3}$ \\ Alisha Wadel \\ Leslie G Womble ${ }^{3}$ \\ Cornelia Dalton-Bakes' \\ Thomas A Wadden ${ }^{3}$ \\ Nayyar Iqbal',2 \\ 'Division of Endocrinology, Diabetes, \\ and Metabolism, Department of \\ Medicine, Hospital of the University \\ of Pennsylvania, Philadelphia, PA, \\ USA; ${ }^{2}$ Division of Endocrinology, \\ Department of Medicine, Philadelphia \\ Veterans Affairs Medical Center, \\ Philadelphia, PA, USA; ${ }^{3}$ Department \\ of Psychiatry, Center for Weight \\ and Eating Disorders, University of \\ Pennsylvania School of Medicine, \\ Philadelphia, PA, USA
}

\begin{abstract}
The effect of dietary macronutrient composition on adipokine concentrations remains unclear. Greater reductions in leptin have been reported in participants who followed low-carbohydrate versus low-fat diets, although these studies did not adjust for the important effects of weight loss on adipokines. We investigated the effect of macronutrient composition on adipokine levels in 144 obese, diabetic participants who were randomly assigned to a low-carbohydrate ( $<30 \mathrm{~g} /$ day) or low-fat diet $(\leq 30 \%$ of calories from fat with a deficit of $500 \mathrm{kcal} /$ day). Weight, adipokines, and dietary intake were assessed at baseline and 6 months. Complete data were available for 79 participants. At month 6, weight, leptin, adiponectin, and tumor necrosis factor- $\alpha$ concentrations did not differ significantly between groups $(P>0.05$ for all variables). However, significant changes in leptin and adiponectin occurred over time ( $P<0.001$ and $P<0.012$, respectively). Modest weight loss, rather than macronutrient composition, likely accounted for the favorable changes observed in leptin and adiponectin over time.
\end{abstract}

Keywords: diet, adipokine, obesity, diabetes, carbohydrate, hormone

\section{Introduction}

Adipocyte-derived hormones, known as adipokines, are important determinants of insulin resistance. ${ }^{1}$ Key adipokines include the insulin-sensitizing hormone, adiponectin, and the proinflammatory hormones, tumor necrosis factor (TNF)- $\alpha$ and leptin. Leptin also plays a role in glucose homeostasis by enhancing the ability of insulin to inhibit hepatic glucose production. ${ }^{2}$ In contrast, TNF- $\alpha$ is believed to impair insulin secretion and has been found to induce $\beta$-cell apoptosis in pancreatic islets isolated from experimental animals and humans. ${ }^{3}$ Weight loss is known to induce favorable changes in adipokine levels in both nondiabetic and diabetic participants, ${ }^{4-6}$ but the relationship between macronutrient intake and adipokines is less clear. ${ }^{7-11}$ Although several studies suggest that weight loss, rather than macronutrient composition, mediates improvements in TNF- $\alpha$ and adiponectin, ${ }^{7-9}$ the effect of dietary intake on leptin has been more variable. ${ }^{10,11}$ Greater reductions in leptin have been reported in persons who followed a low-carbohydrate diet than a low-fat diet, although these studies did not adjust for weight loss. Additionally, previous studies have included mainly nondiabetic individuals; investigators do not know whether the presence of diabetes modifies the effect of macronutrient composition on adipokine concentrations. Thus, we sought to determine the effect of a low-carbohydrate versus a low-fat diet on adiponectin, leptin, and TNF- $\alpha$ levels, independent of weight loss, in obese individuals with diabetes.
Correspondence: Nayyar lqbal Department of Medicine, Division of Endocrinology, Diabetes, and Metabolism, Rodebaugh Diabetes Center, Hospital of the University of Pennsylvania, 4 Penn Tower, 3400 Spruce Street, Philadelphia, PA 19104, USA

Email nayyar.iqbal@uphs.upenn.edu 


\section{Research design and methods}

The present investigation is an exploratory ancillary study to a randomized controlled trial that has been reported in detail previously. ${ }^{12}$ Briefly, 144 obese, diabetic participants were recruited from outpatient clinics at the Philadelphia Veterans Affairs Medical Center, Philadelphia, PA, USA. Inclusion criteria included individuals with type 2 diabetes, aged 18 years and above, and a body mass index $\geq 30 \mathrm{~kg} / \mathrm{m}^{2}$. Exclusion criteria included an $\mathrm{HbA} 1_{c}>12.0 \%$, weight loss $\geq 5 \%$ in the past 3 months, active participation in a weight loss program, and the use of weight-loss medications. Men were randomized in a 1:1 ratio, and women were randomized separately in blocks of four to ensure equal representation in the two dietary conditions. Seventy participants were randomly assigned to a low-carbohydrate $\operatorname{diet}(<30 \mathrm{~g} /$ day without limitations on fat or caloric intake) and 74 to a lowfat diet ( $\leq 30 \%$ calories from fat and a deficit of $500 \mathrm{kcal} /$ day). For the first month, participants in each group attended separate weekly group sessions (led by a registered dietitian), followed by monthly sessions thereafter. All participants received treatment-specific diet handouts, sample menus and recipes, and a book about counting calories and carbohydrates. The Institutional Review Board of the Philadelphia Veterans Affairs Medical Center approved this study. All participants provided written informed consent.

\section{Outcome measures}

Outcome measures were obtained at baseline and month 6 . Weight was measured on a single calibrated scale (SR Instruments, Inc., Tonawanda, NY) at each visit (with participants in light clothing without shoes). Serum total leptin and adiponectin concentrations were measured in duplicate by double antibody radioimmunoassay (Millipore, St Charles, MO). Serum TNF- $\alpha$ was measured by a high sensitivity ELISA (R\&D Systems, Minneapolis, MN). Twenty-four hour dietary recall was collected at baseline and month 6 . All dietary data were analyzed using the Nutribase Management software (Cybersoft, Houston, TX).

\section{Statistical analyses}

Only participants with baseline and month 6 measurements for leptin, adiponectin, and TNF- $\alpha$ were included in the analysis, as the goal was to evaluate the effect of diet on adipokine concentrations. Baseline characteristics were described using means (standard deviations) for continuous data and percentages for categorical variables. Values for leptin, adiponectin, and TNF- $\alpha$ were log transformed prior to analysis to normalize the distribution of the data. Repeated measures ANOVAs (time $\times$ diet group) were performed to compare changes in weight, adipokines, and dietary intake from baseline to month 6 . Correlations were used to examine associations between weight loss and change in adipokine concentrations. Separate multivariable linear regression models were fit for adiponectin, leptin, and TNF- $\alpha$. The dependent variable for each dietary assignment was change in the respective antipokines, and change in weight was included as an explanatory variable. An alpha level of 0.05 was considered statistically significant. Analyses were performed with SPSS 17.0 (SPSS Inc, Chicago, IL).

\section{Results}

Seventy-nine participants (37 in the low-carbohydrate and 42 in the low-fat group) had complete adipokine data at month 6 and were included in the final analysis. A higher attrition rate was seen in the low-carbohydrate condition than in the low-fat condition ( $47.1 \%$ versus $43.2 \%$, respectively), but it was not statistically significant $(P=0.728)$. Most participants who dropped out cited disinterest in the study, difficulty in attending sessions at the Philadelphia Veterans Affairs Medical Center, or frustration with lack of weight loss. Twenty-eight participants did not provide reasons for discontinuing the study.

There were no significant differences between groups at baseline (Table 1). Participants with complete adipokine data did not differ significantly from those who dropped out with

Table I Baseline characteristics of participants randomly assigned to either a low-carbohydrate or low-fat diet

\begin{tabular}{|c|c|c|}
\hline Variable & $\begin{array}{l}\text { Low carbohydrate } \\
(n=37)\end{array}$ & $\begin{array}{l}\text { Low fat } \\
(n=42)\end{array}$ \\
\hline Age, years (SD) & $60.8(10.3)$ & $58.6(9.2$ \\
\hline $\mathrm{BMI}, \mathrm{kg} / \mathrm{m}^{2}$ (SD) & $38.2(6.0)$ & $36.1(4.6$ \\
\hline Male gender, number (\%) & $30(81.8)$ & $40(95.2)$ \\
\hline \multicolumn{3}{|l|}{ Race, number (\%) } \\
\hline White & $14(37.8)$ & $18(42.9)$ \\
\hline Black & $23(62.0)$ & $22(52.4)$ \\
\hline Other & 0 & $2(4.8)$ \\
\hline \multicolumn{3}{|l|}{$\begin{array}{l}\text { Medications for diabetes, } \\
\text { number }(\%)\end{array}$} \\
\hline Insulin & $7(20.0)$ & II (32.4) \\
\hline Metformin & $25(7 \mid .4)$ & $18(52.9)$ \\
\hline Thiazolidinedione & $5(14.3)$ & $6(17.7)$ \\
\hline Sulfonylurea & $23(65.7)$ & $19(55.9)$ \\
\hline Hypertension, number (\%) & $27(73.0)$ & $33(78.6)$ \\
\hline Hyperlipidemia, number (\%) & $21(56.8)$ & $32(76.2)$ \\
\hline $\begin{array}{l}\text { Coronary artery disease, } \\
\text { number }(\%)\end{array}$ & $10(27.0)$ & $13(31.0)$ \\
\hline Cigarette smoking, number (\%) & $4(10.8)$ & $8(19.1)$ \\
\hline
\end{tabular}

Notes: Values are expressed as means (SD), unless otherwise specified. There were no significant baseline differences between groups.

Abbreviations: SD, standard deviation; BMI, body mass index. 
respect to demographic variables, weight and anthropometric measurements, classes of diabetic medications, indices of glycemic control, or diet composition (data not shown).

\section{Change in weight and glycemic parameters}

At month 6, participants in the low-carbohydrate group lost a mean (SD) of $4.0(6.3) \mathrm{kg}$ compared to $2.2(5.3) \mathrm{kg}$ in the low-fat group $(-3.5 \%$ versus $-1.9 \%$ of initial body weight, respectively). Weight declined significantly in all participants $(P<0.001)$ over time, but there were no significant differences between groups $(P=0.181)$. At month 6 , waist circumference did not differ significantly between groups $(P=0.700)$. HbA1c decreased by $0.6 \%$ in the low-carbohydrate group and by $0.1 \%$ in the low-fat group at month 6 , although the difference did not reach statistical significance. Changes in weight, waist circumference, glycemic parameters, and adipokine concentrations are shown in Table 2.

\section{Changes in leptin, adiponectin, and TNF- $\alpha$}

Leptin decreased in both dietary conditions at month 6 (Table 2), but changes between groups were not significant $(P=0.320)$. Leptin decreased significantly by $18 \%$ $(-4.4[12.7] \mathrm{ng} / \mathrm{mL} ; P<0.001)$ from baseline to month 6

Table 2 Between group comparisons of the change in weight, adipokines, and metabolic data from baseline to month 6

\begin{tabular}{|c|c|c|}
\hline Variable & $\begin{array}{l}\text { Low carbohydrate } \\
(n=37)\end{array}$ & $\begin{array}{l}\text { Low fat } \\
(n=42)\end{array}$ \\
\hline \multicolumn{3}{|l|}{ Weight, kg } \\
\hline Baseline & I $8.7(24.4)$ & II $5.4(22.3)$ \\
\hline$\Delta$ from baseline to month 6 & $-4.0(6.3)$ & $-2.2(5.3)$ \\
\hline \multicolumn{3}{|l|}{ Waist circumference, $\mathrm{cm}$} \\
\hline Baseline & $121.0(21.4)$ & $121.9(10.4)$ \\
\hline$\Delta$ from baseline to month 6 & $-2.4(21.7)$ & $2.4(4.4)$ \\
\hline \multicolumn{3}{|l|}{ Adiponectin, $\mu g / m L$} \\
\hline Baseline & I3.4 (9.1) & $16.0(9.9)$ \\
\hline$\Delta$ from baseline to month 6 & $2.6(8.4)$ & $4.3(14.6)$ \\
\hline \multicolumn{3}{|l|}{ Leptin, ng/mL } \\
\hline Baseline & $25.2(14.7)$ & $22.2(18.3)$ \\
\hline$\Delta$ from baseline to month 6 & $-3.0(11.9)$ & $-5.6(13.3)$ \\
\hline \multicolumn{3}{|l|}{ TNF- $\alpha, p g / m L$} \\
\hline Baseline & $3.4(7.1)$ & $1.9(1.1)$ \\
\hline$\Delta$ from baseline to month 6 & $-1.5(7.1)$ & $-1.5(5.6)$ \\
\hline \multicolumn{3}{|l|}{ Insulin, $\mu \mathrm{U} / \mathrm{mL}$} \\
\hline Baseline & $22.9(12.9)$ & $26.8(18.1)$ \\
\hline$\Delta$ from baseline to month 6 & $-3.7(12.1)$ & $1.9(25.2)$ \\
\hline \multicolumn{3}{|l|}{ HbAlc, \% } \\
\hline Baseline & $8.1(1.8)$ & $7.3(1.5)$ \\
\hline$\Delta$ from baseline to month 6 & $-0.6(1.2)$ & $-0.1(1.2)$ \\
\hline
\end{tabular}

Notes: Values are expressed as mean (standard deviation), unless otherwise specified. Weight, adipokines, and metabolic data did not differ significantly between groups at any point. across groups. Adiponectin increased in both conditions by month 6 , but again there were no significant differences between groups $(P=0.777)$. However, a significant increase in adiponectin (25\%) was observed over time $(+3.5[12.1] \mathrm{ng} / \mathrm{mL} ; P<0.012)$. Similar to leptin and adiponectin, TNF- $\alpha$ concentrations did not differ significantly between groups. Although TNF- $\alpha$ decreased modestly in both groups from baseline to month 6 , the change did not differ significantly with time $(P=0.340)$ or by dietary assignment $(P=0.475)$.

Weight loss at month 6 was significantly associated with changes in leptin $(r=0.36 ; P=0.001)$ and TNF- $\alpha(r=-0.29$; $P=0.014)$, but not adiponectin $(r=-0.07 ; P=0.539)$. Thus, individuals who lost more weight had greater reductions in leptin and TNF- $\alpha$. In multivariable linear regression analysis, dietary assignment was not associated with change in any of the adipokine concentrations after controlling for weight loss (Table 3). However, there was a trend toward a greater decrease in leptin in the low-fat group, after controlling for weight loss $(P=0.090)$.

\section{Changes in dietary intake}

Caloric intake did not differ significantly between groups $(P=0.319)$, but decreased significantly over time by 263.2 $(1022.4) \mathrm{kcal} /$ day $(P=0.035)$. The distribution of macronutrient intake did not differ significantly between groups at month 6 (Table 4).

\section{Discussion}

This investigation examined the effect of macronutrient composition on adipokine concentrations, independent of weight loss, in obese individuals with diabetes. Changes in adiponectin, leptin, and TNF- $\alpha$ concentrations did not differ significantly between dietary groups at 6 months.

Table 3 Results from the multiple linear regression model to examine the association between dietary assignment and change in adipokines, while controlling for weight change from baseline to month 6

\begin{tabular}{llll}
\hline Variable & Coefficient & $\begin{array}{l}\text { 95\% confidence } \\
\text { interval }\end{array}$ & P value \\
\hline Adiponectin & & $-0.113,0.069$ & 0.636 \\
Diet assignment & -0.056 & $-0.11,0.12$ & 0.927 \\
Weight change & 0.016 & $-0.012,0.165$ & 0.090 \\
Leptin & & $0.009,0.032$ & 0.001 \\
Diet assignment & 0.183 & & \\
Weight change & 0.573 & $-2.07,0.149$ & 0.749 \\
TNF- $\alpha$ & & $-0.005,0.48$ & 0.110 \\
Diet assignment & -0.038 & & \\
Weight change & 0.313 & &
\end{tabular}


Table 4 Between group comparisons of the change in dietary intake from baseline to month 6

\begin{tabular}{|c|c|c|}
\hline Variable & $\begin{array}{l}\text { Low carbohydrate } \\
(n=37)\end{array}$ & $\begin{array}{l}\text { Low fat } \\
(n=42)\end{array}$ \\
\hline \multicolumn{3}{|l|}{ Caloric intake, kcal } \\
\hline Baseline & $2056.0(762.2)$ & $1967(708.1)$ \\
\hline$\Delta$ from baseline to month 6 & $-138.9(1216.8)$ & $-380.7(796.3)$ \\
\hline \multicolumn{3}{|l|}{ Carbohydrate, $g$} \\
\hline Baseline & $202.4(I \mid 2.2)$ & $211.2(84.8)$ \\
\hline$\Delta$ from baseline to month 6 & $-46.7(127.6)$ & $-37.1(123.4)$ \\
\hline \multicolumn{3}{|l|}{ Protein, $\mathrm{g}$} \\
\hline Baseline & $94.0(50.5)$ & $88.2(36.7)$ \\
\hline$\Delta$ from baseline to month 6 & $-8.1(6 \mid .4)$ & $-2.8(45.7)$ \\
\hline \multicolumn{3}{|l|}{ Fat, g } \\
\hline Baseline & $98.7(45.3)$ & $87.9(5 \mathrm{I} .1)$ \\
\hline$\Delta$ from baseline to month 6 & $-5.9(63.9)$ & $-23.3(48.8)$ \\
\hline
\end{tabular}

Notes: Values are expressed as mean (standard deviation), unless otherwise specified. Dietary intake did not differ significantly between groups at any point.

However, despite very modest weight loss, significant and favorable changes in adiponectin and leptin occurred over time. This finding is consistent with three recent reports of significant increases in adiponectin with as little as $5 \%$ weight loss. ${ }^{13-15}$

Leptin decreased significantly over time and was significantly associated with weight loss. Miller and colleagues reported similar reductions in leptin in women who achieved equivalent weight loss on either a lowcarbohydrate or low-fat diet, suggesting that weight loss, rather than macronutrient composition, accounts for the change. ${ }^{7}$ Two recent studies reported significantly lower leptin concentrations in participants who followed a lowcarbohydrate diet, but failed to adjust for weight loss. ${ }^{9,10}$ Findings from the present study further support the notion that favorable changes in leptin are mediated primarily by weight loss.

Although several studies have reported significant changes in adipokines with very modest weight loss similar to that achieved in the present study, the presence of diabetes may have attenuated changes in response to weight loss. In a small study that compared changes in adipokine concentrations between diabetic and nondiabetic participants who achieved substantial and equivalent weight loss following gastric bypass, Whitson and colleagues reported significant changes in adiponectin and TNF- $\alpha$ levels only in the nondiabetic participants. ${ }^{16}$ Leptin decreased significantly within both groups. The authors speculated that physiologic responses to weight loss differ between individuals with and without diabetes, and this may account for the favorable changes in adipokine concentrations observed in the nondiabetic participants. Further studies are needed to corroborate this finding and explore the potential mechanisms by which diabetes may attenuate favorable changes in adipokine levels in response to weight loss.

The present study had several limitations. Because both groups failed to fully achieve their dietary targets at month 6 , we cannot draw firm conclusions about the effect of macronutrient composition on adipokine levels. However, caloric intake was similar between groups at month 6 , suggesting that caloric restriction and weight change were the principal determinants of changes in adipokines, rather than macronutrient intake. Based on the reported caloric deficit and the actual weight change at month 6 , it appears that participants in both groups (particularly those in the low-fat group) substantially underestimated their intake. Because a 24 -h food recall has modest reliability and validity, ${ }^{17}$ a 3-day food record may have better captured typical dietary intake. Many participants did not return for follow-up at month 6. However, comparable attrition rates of $40 \%-50 \%$ have been reported in several studies that compared lowcarbohydrate and low-fat diets, with lack of interest in the diet or failure to lose weight commonly cited as reasons for study discontinuation. ${ }^{18-21}$ As the purpose of the study was to evaluate the effect of dietary intake on adipokine concentrations, only participants who had data at baseline and month 6 were included in the analysis. Power to detect differences between groups was reduced because of the small sample size. In addition, we were unable to assess the independent effect of diabetes because nondiabetic individuals were excluded from the study.

This study highlights the beneficial effects of very modest weight loss on adiponectin and leptin, regardless of dietary macronutrient composition. As the weight loss achieved in both groups did not differ significantly from one another, the present study reinforces the concept that any type of diet can effectively reduce weight and improve metabolic parameters. ${ }^{22}$ Diets that can be tailored to individual patients according to their personal preferences may have the greatest likelihood of achieving long-term success with weight loss and maintenance.

In summary, weight, adipokine levels, and dietary intake did not differ significantly between dietary groups at 6 months. Modest weight loss, rather than macronutrient composition, likely accounted for the favorable changes observed in leptin and adiponectin over time. The relationship between macronutrient composition and change in adipokine levels should be evaluated separately in diabetic and nondiabetic populations to investigate the potential for effect modification by diabetes status. 


\section{Acknowledgments}

This study is dedicated to the memory of Frederick F Samaha, MD, in recognition of his many contributions to this research. We gratefully acknowledge the contributions of Rosa Kim, BS, and Sara Ali, MD, for their assistance with study management. We thank Heather Collins, $\mathrm{PhD}$, from the Diabetes Endocrinology Research Center at the University of Pennsylvania, for performing the adipokine assays. We thank J Graham Thomas, PhD, for his assistance with the statistical analysis.

Grant Support: VA Merit Review Entry Program.

\section{Disclosure}

The authors have no conflict of interest to disclose. Dr Iqbal is currently employed at Bristol-Myers Squibb, but remains an adjunct faculty member at the University of Pennsylvania School of Medicine. He was a full-time faculty member at the University of Pennsylvania and at the Philadelphia Veterans Affairs Medical Center during the period in which the study was conducted.

\section{References}

1. Rasouli N, Kern PA. Adipocytokines and the metabolic complications of obesity. J Clin Endocrinol Metab. 2008;93:S64-S73.

2. Rossetti L, Massillon D, Barzilai N, et al. Short term effects of leptin on hepatic gluconeogenesis and in vivo insulin action. J Biol Chem. 1997; 272:27758-27763.

3. Ishizuka N, Yagui K, Tokuyama Y, et al. Tumor necrosis factor alpha signaling pathway and apoptosis in pancreatic beta cells. Metabolism. 1999;48:1485-1492.

4. Wadden TA, Considine RV, Foster GD, Anderson DA, Sarwer DB, Caro JS. Short- and long-term changes in serum leptin dieting obese women: effects of caloric restriction and weight loss. J Clin Endocrinol Metab. 1998;83:214-218.

5. Wing RR, Sinha MK, Considine RV, Lang W, Caro JF. Relationship between weight loss maintenance and changes in serum leptin levels. Horm Metab Res. 1996;28:698-703.

6. Trakhtenbroit MA, Leichman JG, Algahim MF, et al. Body weight, insulin resistance, and serum adipokine levels 2 years after 2 types of bariatric surgery. Am J Med. 2009;122:435-442.

7. Miller LE, Volpe JJ, Coleman-Kelly MD, Gwazdauskas FC, NickolsRichardson SM. Anthropometric and leptin changes in women following different dietary approaches to weight loss. Obesity. 2008;17: 199-201.
8. Arvidsson E, Viguerie N, Anderson I, Verdich C, Langin D, Arner P. Effects of different hypocaloric diets on protein secretion from adipose tissue of obese women. Diabetes. 2004;53:1966-1971.

9. Cardillo S, Seshadri P, Iqbal N. The effects of a low-carbohydrate versus low-fat diet on adipocytokines in severely obese adults: three-year follow-up of a randomized trial. Eur Rev Med Pharmacol Sci. 2006;10: 99-106.

10. Seshadri P, Samaha FF, Stern L, Ahima RS, Daily D, Iqbal N. Adipocytokine changes caused by low-carbohydrate compared to conventional diets in obesity. Metab Syndr Relat Disord. 2005;3:66-74.

11. de Luis DA, Aller R, Izaola O, Gonzalez-Sagrado M, Bellioo D, Conde R. Effects of a low-fat versus low-carbohydrate diet on adipocytokines in obese adults. Horm Res. 2007;67:296-300.

12. Iqbal N, Vetter ML, Moore RH, et al. Effects of a low-intensity intervention that prescribed a low-carbohydrate vs. a low-fat diet in obese, diabetic participants. Obesity (Silver Spring). 2010;18:1733-1738.

13. Al-Sarraj T, Saadi H, Calle MC, Volek JS, Fernandez ML. Carbohydrate restriction, as a first-line dietary intervention, effectively reduces biomarkers of metabolic syndrome in Emirati adults. J Nutr. 2009;139: 1667-1676.

14. Keogh JB, Brinkworth GD, Clifton PM. Effects of weight loss on a low-carbohydrate diet on flow-mediated dilatation, adhesion molecules and adiponectin. Br J Nutr. 2007;98:852-859.

15. Varady KA, Tussing L, Bhutani S, Braunschweig CL. Degree of weight loss required to improve adipokine concentrations and decrease fat cell size in severely obese women. Metabolism. 2009;58:1096-1101.

16. Whitson BA, Leslie DB, Kellog TA, et al. Adipokine response in diabetics and nondiabetics following Roux-en-Y gastric bypass: a preliminary study. J Surg Res. 2007;142:295-300.

17. Hise ME, Sullivan DK, Jacobsen DJ, Johnson SL, Donnelly JE. Validation of energy intake measurements determined from observer-recorded food records and recall methods compared with the doubly labeled water method in overweight and obese individuals. Am J Clin Nutr. 2002;75: 263-267.

18. Foster GD, Wyatt HR, Hill JO, et al. A randomized trial of a lowcarbohydrate diet for obesity. N Engl J Med. 2003;348:2082-2090.

19. Samaha FF, Iqbal N, Seshadri P, et al. A low-carbohydrate as compared with a low-fat diet in severe obesity. N Engl J Med. 2003;348: 2074-2081.

20. Dansinger ML, Gleason JA, Griffith JL, Selker HP, Schaefer EJ. Comparison of the Atkins, Ornish, Weight Watchers, and Zone diets for weight loss and heart disease risk reduction: a randomized trial. JAMA. 2005;293:43-53.

21. Westman EC, Yancy WS Jr, Mavropoulos JC, Marquart M, McDuffie JR. The effect of a low-carbohydrate, ketogenic diet versus a low-glycemic index diet on glycemic control in type 2 diabetes mellitus. Nutr Metab. 2008;5:36.

22. Sacks FM, Bray GA, Carey VJ, et al. Comparison of weight-loss diets with different compositions of fat, protein, and carbohydrates. $N \mathrm{Engl}$ J Med. 2009;360:859-873.

\section{Publish your work in this journal}

Diabetes, Metabolic Syndrome and Obesity: Targets and Therapy is an international, peer-reviewed open-access journal committed to the rapid publication of the latest laboratory and clinical findings in the fields of diabetes, metabolic syndrome and obesity research. Original research, review, case reports, hypothesis formation, expert opinion and commentaries are all considered for publication. The manuscript management system is completely online and includes a very quick and fair peer-review system, which is all easy to use. Visit http://www.dovepress.com/testimonials.php to read real quotes from published authors. 